Malaria Journal

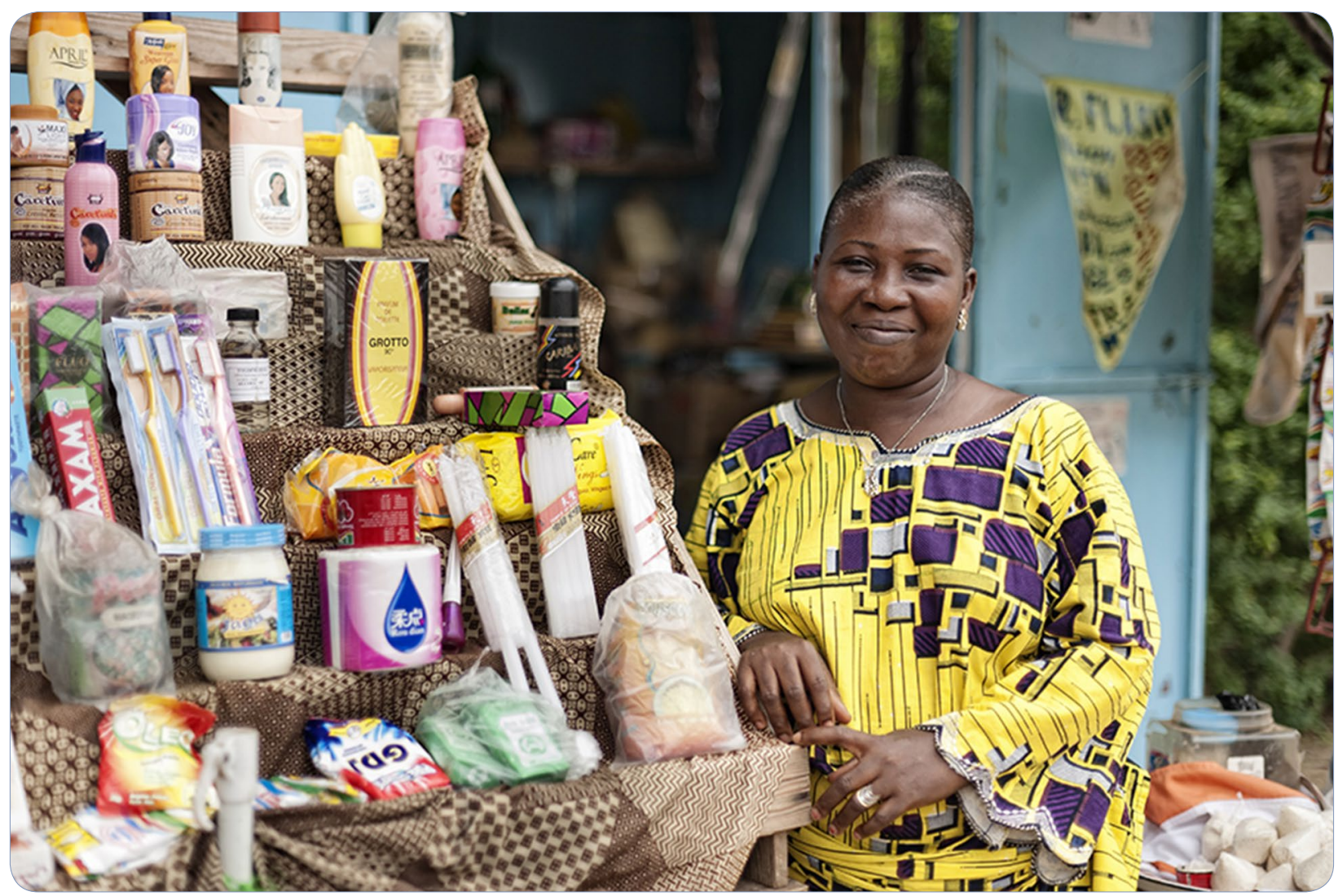

\title{
The malaria testing and treatment landscape in Benin
}

ACTwatch Group et al.

C Biomed Central 


\title{
The malaria testing and treatment landscape in Benin
}

\author{
ACTwatch Group ${ }^{1 *}$, Cyprien Zinsou ${ }^{2^{*}}$ and Adjibabi Bello Cherifath ${ }^{3}$
}

\begin{abstract}
Background: Since 2004, artemisinin-based combination therapy (ACT) has been the first-line treatment for uncomplicated malaria in Benin. In 2016, a medicine outlet survey was implemented to investigate the availability, price, and market share of anti-malarial treatment and malaria diagnostics. Results provide a timely and important benchmark to measure future interventions aimed at increasing access to quality malaria case management services.

Methods: Between July 5th to August 6th 2016, a cross sectional, nationally-representative malaria outlet survey was conducted in Benin. A census of all public and private outlets with potential to distribute malaria testing and/or treatment was implemented among 30 clusters (arrondissements). Outlets were eligible for inclusion in the study if they met at least one of three study criteria: (1) one or more anti-malarials reportedly in stock on the day of the survey; (2) one or more anti-malarials reportedly in stock within the 3 months preceding the survey; and/or (3) provided malaria blood testing. An audit was completed for all anti-malarials, malaria rapid diagnostic tests (RDT) and microscopy.
\end{abstract}

Results: 7260 outlets with the potential to sell or distribute anti-malarials were included in the census and 2966 were eligible and interviewed. A total of 17,669 anti-malarial and 494 RDT products were audited. Quality-assured ACT was available in $95.0 \%$ of all screened public health facilities and $59.4 \%$ of community health workers (CHW), and availability of malaria blood testing was 94.7 and $68.4 \%$ respectively. Sulfadoxine-pyrimethamine (SP) was available in $73.9 \%$ of public health facilities and not found among CHWs. Among private-sector outlets stocking at least one antimalarial, non-artemisinin therapies were most commonly available ( $94.0 \%$ of outlets) as compared to quality-assured ACT (36.1\%). 31.3\% of the ACTs were marked with a "green leaf" logo, suggesting leakage of a co-paid ACT into Benin's unsubsidized ACT market from another country. $78.5 \%$ of the anti-malarials distributed were through the private sector, typically through general retailers (47.6\% of all anti-malarial distribution). ACT comprised $44 \%$ of the private anti-malarial market share. Private-sector price of quality-assured ACT $(\$ 1.35)$ was three times more expensive than SP $(\$ 0.42)$ or chloroquine $(\$ 0.41)$. Non-artemisinin therapies were cited as the most effective treatment for uncomplicated malaria among general retailers and itinerant drug vendors.

Conclusions: The ACTwatch data has shown the importance of the private sector in terms of access to malaria treatment for the majority of the population in Benin. These findings highlight the need for increased engagement with the private sector to improve malaria case management and an immediate need for a national ACT subsidy.

Keywords: Benin, Malaria case management, Private sector, Public sector, Artemisinin-based combination therapy, Diagnostic test, ACT subsidy

\footnotetext{
*Correspondence: mlittrell@psi.org; czinsou@abmsbj.org

1 Population Services International, 1120 19th St NW Suite 600, Washington, DC 20036, USA

${ }^{2}$ Association Beninoise pour le Marketing Social, Lot 919 Immeuble

Montcho, Sikecodji, Cotonou, Republic of Benin

Full list of author information is available at the end of the article
} provided you give appropriate credit to the original author(s) and the source, provide a link to the Creative Commons license, and indicate if changes were made. The Creative Commons Public Domain Dedication waiver (http://creativecommons.org/ publicdomain/zero/1.0/) applies to the data made available in this article, unless otherwise stated. 


\section{Background}

In Benin, important gains in malaria control have been achieved in recent years, however, malaria remains a leading cause of morbidity and mortality. In 2015, the World Health Organization (WHO) reported over two million confirmed malaria cases and 1416 deaths in the country [1]. Malaria is cited as the leading reason for medical consultations and hospitalization in Benin [2]. According to population based surveys, only $28 \%$ of children under 5 received the first-line treatment for uncomplicated malaria [3] and among pregnant women, only one in four were found to use intermittent treatment as prevention during pregnancy (IPTp) [4]. The financial impact of malaria is also of concern in Benin. It is estimated that households spend approximately one-quarter of their annual income on the prevention and treatment of malaria, meanwhile, $37 \%$ of the Benin population live below the poverty line, with a per capita annual income of only $\$ 750$ [5].

In 2004, the policy for malaria management in Benin changed when the National Malaria Control Programme (NMCP) introduced artemisinin-based combination therapy $(\mathrm{ACT})$, artemether-lumefantrine $(\mathrm{AL})$, for treatment of uncomplicated malaria [1]. Up to that time, chloroquine had been used for first-line therapy against uncomplicated malaria. In 2011, the guidelines changed and stipulated that patients of all ages should receive a confirmatory malaria test prior to treatment. In 2014, updates to national policy brought malaria to case management guidelines further inline with WHO recommendations and stipulated three doses of sulfadoxine-pyrimethamine (SP) for IPTp. The NMCP also updated the malarial national case management guidelines to align with the WHO recommendation for treatment of severe malaria with injectable artesunate and injectable artemether [6], though injectable quinine is also still recommended followed by a seven day treatment with oral quinine. Treatment for severe malaria should only be administered at a public or private hospital. Oral artemisinin monotherapies have been banned in Benin since 2008 [1].

As a means to promote universal coverage of first-line treatment and increase rates of confirmatory testing, the NMCP took significant steps to improve malaria case management services across the country. In 2011, publicsector initiatives included free malaria case management to children under 5 years of age and pregnant women. Prior to this, public health facilities had charged fees for consultation, medications, and procedures [7]. The 20142018 National Malaria Strategic Plan was also developed and set the goal that by 2030, “...malaria would no longer be a public health problem in Benin" [6]. The strategy aims to decrease the number of annual cases by $75 \%$ and reduce the mortality rate to 1 death per 100,000 people.

There has been a substantial increase in the procurement of ACT and malaria rapid diagnostic tests (RDT) as a means to increase universal access to malaria commodities. In 2014, over 1.3 million RDT were procured and in 2015, this increased to almost 1.5 million [1]. A similar pattern followed for the procurement of ACT, which increased from 1.1 million in 2014 to 1.2 million in 2015. Commodities such as ACT and RDT have largely been made available through the public-sector channels.

Other initiatives to improve malaria case management services include expanding access to primary health care services through the training and equipping of community health workers (CHW), including training on the appropriate use of RDT as well as the management of malaria, pneumonia, diarrhoea, and malnutrition [6]. In 2014, it was estimated that over $12,500 \mathrm{CHW}$ were active in the country. Other public-sector initiatives have included funds for the provision of free healthcare to the extremely poor, and the reinforcement of health financing schemes [8].

There have been no major initiatives targeting the private sector in Benin to improve malaria case management services, despite evidence that over $70 \%$ of antimalarials are distributed through this channel [9]. While the national strategy has included the provision of diagnosis, microscopy or RDT, and ACT in selected private health clinics [10], the scale-up is largely in process and has yet to be routinely implemented [6]. Indeed, the private sector in Benin is renowned for being diverse and continuously expanding, with most providers operating informally without a license, mainly because the accreditation process is often perceived as difficult and conveying few benefits $[6,11]$. While there is a push to simplify the process by bringing more of the private sector into the formal market, this has yet to be widely implemented.

This lack of private-sector engagement contrasts with several other countries that have benefitted from ACT subsidies aimed to increase access to first-line treatment in the private sector. The most notable of these initiatives was the Affordable Medicines Facility-malaria (AMFm), which continued through 2016 [12,13] and was implemented in neighbouring Nigeria, as well as seven other countries (Cambodia, Ghana, Kenya, Madagascar, Niger, Uganda, and Tanzania). Through this mechanism, subsidized ACT was available on the market and labelled with a 'green leaf' logo to indicate quality-assurance. By increasing quality-assured ACT on the anti-malarial market, the AMFm also aimed to decrease the use of oral artemisinin monotherapies, and non-artemisinin monotherapies, such as chloroquine. Following the AMFm pilot period, the Global Fund continued to support a quality-assured ACT subsidy programme through the Private Sector Co-payment Mechanism (CPM) [14], but Benin was not part of this initiative.

Investigating the anti-malarial and diagnostic market landscape will provide an important benchmark to 
measure future interventions aimed at increasing access to quality malaria case management services. However, there is limited rigorous evidence on the availability and distribution of anti-malarials and malaria diagnostics in Benin. Since 2008, the multi-country ACTwatch project has been implemented in Benin to fill contemporary evidence gaps by collecting malaria case management commodity market data on anti-malarial medicines, malaria diagnostics, market share, and price in both the private and public sectors [15]. The objective of this paper is to provide practical evidence to inform strategies and policies in Benin towards achieving national malaria control goals, by describing the total market for malaria medicines and diagnostics at the national level according to the most recent survey round. Evidence will point to recommendations for improving coverage of appropriate malaria case management.

\section{Methods}

This was the fourth outlet survey implemented in Benin, with previous surveys conducted in 2009, 2011, and 2014 [16-18]. This study used a cross-sectional, multi-staged cluster sampling approach and was stratified according to urban/rural areas. The outlet survey followed the design implemented in previous survey rounds and across other ACTwatch countries. The outlet survey was implemented from July 5th to August 6th 2016.

\section{Sampling approach}

According to the ACTwatch methodology, outlets are included in the survey if they have the 'potential' to sell or distribute anti-malarials. This includes outlets that may not be expected to stock anti-malarial medicines. For example, while public health facilities would be expected to have anti-malarials in stock, the extent to which general retailers or itinerant drug vendors have anti-malarials available may be more debatable. To assess this, the ACTwatch study approach is to include all outlets that could 'potentially stock' anti-malarials.

Outlets sampled in Benin's public sector included public health facilities (including the national referral hospital, regional hospitals, district hospitals, health centers and dispensaries); $\mathrm{CHW}$ and private not-forprofit facilities (including non-governmental organisations, hospitals and clinics, and faith-based hospitals and clinics). The private-sector outlet types sampled were private for-profit health facilities (including private hospitals, clinics and diagnostic laboratories); pharmacies (which are registered and licensed by a national regulatory authority); drug stores (Depôts pharmaceutiques); general retailers (grocery stores, kiosks and market stalls selling fast-moving consumer products); and itinerant drug vendors (mobile, unregistered providers selling medicines).
The primary sampling approach taken for ACTwatch outlet surveys entails sampling a set of administrative units (geographic clusters) with a population of approximately 10,000-15,000 inhabitants. The most appropriate administrative unit in Benin matching the desired population size was an 'arrondissement'. A representative sample of arrondissements was selected using probability proportional to population size sampling, using data from Benin's fourth Population and Housing census.

As public health facilities, pharmacies, and drug shops (dépôts pharmaceutiques) are important providers of anti-malarials but are relatively uncommon, oversampling was conducted for these outlet types in Benin. This 'booster' sample was obtained by including all public health facilities, pharmacies, and drug shops (dépôts pharmaceutiques) located in the larger administrative area (called a 'commune' in Benin) from which a given arrondissement was selected. In this instance, the booster sample covered all public health facilities, pharmacies, and drug shops in the whole commune within which the arrondissements were located.

The sample was stratified by urban-rural ward designation. In total, 15 arrondissement were selected for the main census sample (15 rural, 15 urban). Within each selected arrondissement a census of all outlet types with the potential to provide anti-malarials or diagnostics to consumers was undertaken.

\section{Eligibility criteria}

Outlets were eligible for a provider interview and malaria product audit if they met at least one of three study criteria: (1) one or more anti-malarials reportedly in stock on the day of the survey; (2) one or more anti-malarials reportedly in stock within the three months preceding the survey; and/or (3) provided malaria blood testing (microscopy or RDT). Among eligible outlets, providers were interviewed and all anti-malarials and RDTs were audited.

\section{Sample size}

A series of calculations was completed to identify minimum sample size requirements to detect an increase or decrease in the availability of quality-assured ACT and of malaria blood testing between 2014 and 2016. Calculations examined the sample size required to detect a $20 \%$ point change among all outlets, the public sector, the private sector, public health facilities, pharmacies, and general retail outlets.

The required sample size for each research domain (urban and rural areas) was calculated in three steps: (1) determine the required number of anti-malarial-stocking outlets, (2) determine the number of outlets to be enumerated to arrive at this number of anti-malarial-stocking outlets, and (3) determine the number of arrondissement for the census to arrive at this number of outlets. 


\section{Required number of anti-malarial stocking outlets}

The number of anti-malarial-stocking outlets required to detect a change over time is given by:

$$
n=\frac{\operatorname{deff} \times\left[Z_{1-\alpha} \sqrt{2 P(1-P)}+Z_{1-\beta} \sqrt{P_{1}\left(1-P_{1}\right)+P_{2}\left(1-P_{2}\right)}\right]^{2}}{\left(P_{2}-P_{1}\right)^{2}}
$$

where $n=$ desired sample size, $\mathrm{P}_{1}=$ the proportion of anti-malarial-stocking outlets with quality-assured ACT/ malaria blood testing available in stock in 2014, $\mathrm{P}_{2}=$ the expected proportion of anti-malarial-stocking outlets with quality-assured ACT/malaria blood testing available in stock in 2016 (20\% point increase or decrease), $\mathrm{P}=\left(\mathrm{P}_{1}+\mathrm{P}_{2}\right) / 2, \mathrm{Z}_{\alpha}=$ the standard normal deviation value for an $\alpha$ type I error (two-sided), $Z_{1-\beta}=$ the standard normal deviation value for a $\beta$ type II error, Deff $=$ the design effect in case of multi-stage arrondissement sample design. Deff figures from the 2014 dataset were used in sample size calculations.

\section{Required number of outlets}

The estimated number of outlets enumerated needed for the quality-assured ACT availability indicator was determined by the following formula for outlets within urban and rural domains:

$$
\mathrm{N}=\mathrm{n} / \mathrm{P}_{\mathrm{am}}
$$

where $\mathrm{P}_{\mathrm{am}}$ is the proportion of outlets having antimalarial stocks at the time of the survey among all outlets enumerated. In this equation, the assumptions are as follows: $\mathrm{N}=$ desired sample size of all outlets for monitoring availability indicators, $\mathrm{n}$ is the number of outlets with anti-malarial stocks at the time of the survey. $\mathrm{P}_{\mathrm{am}}$ is the proportion of outlets having anti-malarials in stock at the time of the survey among outlets enumerated in 2014 within urban and rural areas. The $\mathrm{P}_{\mathrm{am}}$ values documented in the 2014 ACTwatch outlet survey were used for 2016 sample size calculations.

\section{Required number of arrondissements}

The average numbers of outlets by outlet type in arrondissements within urban and rural areas screened during the 2014 outlet survey were used to estimate the number of arrondissements required in 2016 to achieve the desired sample sizes. Considering sample size requirements to detect change over time and average numbers of outlets across each outlet type, the optimal minimum number of localities required to reach desired numbers of outlets was 30 arrondissements (15 urban, 15 rural) plus a booster sample of public health facilities, pharmacies, and drug shops at the commune level.

\section{Data collection}

The outlet survey census involved systematically looking for outlets in each arrondissement and using screening questions to identify outlets for inclusion in the study. Provider interviews and anti-malarial audits were conducted in all eligible outlets, after informed consent procedures. Up to three call-back visits were made to outlets in instances where outlets were closed or providers were not available.

Data were collected using Android phones, except in pharmacies that had a large number of anti-malarial products. In these pharmacies, paper questionnaires were used so that multiple interviewers could audit antimalarial products simultaneously to shorten the time required to finish the interview. The electronic data collection program was developed using DroidDB (C SYWARE, Inc., Cambridge, MA, USA).

\section{Measures}

Anti-malarial audit information recorded information on the formulation, package size, brand name, active ingredients and strength(s), manufacturer, country of manufacture, reported sale/distribution in the week preceding the survey, retail price, and wholesale price. The RDT audit information collected similar data. In addition to the product audit, a series of questions were administered to the senior-most provider regarding malaria case management knowledge and practices as well as provider training and qualifications.

\section{Training}

Standard ACTwatch tools and training materials were used. A training of trainers was conducted in June 2016 and was followed by a pilot test to evaluate the electronic data collection program. Interviewers, supervisors, and quality controllers then received a training that included an orientation to the study, questionnaire overview, including a focus on how to complete the anti-malarial and RDT audits and how to use the electronic data collection program.

After the training, a field exercise was conducted outside of the selected arrondissements to provide practical experience for the trainees and to evaluate their performance. Supervisors and quality controllers were then chosen from the highest performers in the group, and these candidates then participated in an additional three-day training before the start of data collection. Eight teams were formed, each composed of one supervisor, one quality controller, and five or six interviewers. Representatives from the research agency, Association Beninoise pour le Marketing Social (ABMS), and the ACTwatch central team provided additional supervision and support to the data collection teams in the field for the entirety of the data collection. 


\section{Data analysis}

Data collected with paper questionnaires were double entered and verified using a Microsoft Access database. All data cleaning and analysis was completed using Stata 13.1 (@StataCorp, College Station, TX). Sampling weights were applied to account for variations in the probability of selection and standard error estimation accounted for clustering at the arrondissement and commune levels. The sampling weights use for the Benin survey are described in further detail in Additional file 1.

Standard ACTwatch indicators were calculated in line with previous outlet surveys [9, 15, 19]. Anti-malarials were classified as ACT, non-artemisinin therapy, and oral or non-oral artemisinin monotherapy. ACT were further classified as quality-assured ACT or non-quality assured ACT by matching product information to lists of WHO prequalified anti-malarials and Global Fund anti-malarial procurement lists.

Availability of any anti-malarial was calculated with all screened outlets as the denominator. In the public sector, the availability of specific types of anti-malarials was calculated using the denominator of all screened outlets given that anti-malarials should be available at all public health facilities and among CHWs. Availability of specific anti-malarial categories in the private sector was calculated using the total number of private-sector outlets stocking any anti-malarial as the denominator.

Market share was defined as the relative distribution of anti-malarials to individual consumers in the week preceding the survey. In order to allow for meaningful market share comparisons between products, information about anti-malarial distribution was standardized to the adult equivalent treatment dose (AETD). AETD is the amount of active ingredient necessary to treat a $60 \mathrm{~kg}$ adult according to WHO treatment guidelines [20]. Volumes distributed were calculated by converting provider reports on the number of anti-malarials sold in the week prior to the survey into AETDs. Volumes were therefore the number of AETDs sold or distributed by a provider in the seven days prior to the survey. All dosage forms were considered when measuring volumes to provide a complete assessment of anti-malarial market share. Public and private-sector booster sample outlets were excluded from market share calculations to avoid over-estimating the role of the private sector.

Median private sector price per AETD was calculated for quality-assured ACT and other non-artemisinin therapies including chloroquine, SP, and quinine. The interquartile range [IQR] was calculated to demonstrate price dispersion. Anti-malarial price was collected in West African Communauté Financière Africaine (CFA) and converted to United States (US) dollars based on official exchange rates for the six-week data collection period.
Provider perceptions regarding the most effective firstline treatment was assessed by administering questions to the senior most provider at all anti-malarial-stocking outlets. Providers were asked to describe what medicine they believed was the most effective treatment for treating uncomplicated malaria in a child and in an adult.

\section{Results}

A total of 7260 outlets were screened for availability of anti-malarials and/or malaria blood testing services. Of screened outlets 2966 met one of the three screening criteria, including 2959 who were stocking anti-malarials on the day of the survey or within the past three months or provided malaria testing. A total of 17,669 anti-malarial and 494 RDT products were audited (Additional file 2).

\section{Public sector availability}

Table 1 shows the availability among all screened public sector outlets. Availability of any anti-malarial was $95.0 \%$ among public health facilities and $59.4 \%$ among CHWs. Nine in ten public health facilities stocked quality-assured ACT (89.9\%) and 54.8\% of CHWs. Among public health facilities, availability of the four different package AL pack sizes $(6,12,18$ and 24 tablets) suitable for management of four different weight categories of patients $(5-14 ; 15-24$; $25-34$ and $\geq 35 \mathrm{~kg}$ ) ranged from 48.8 to $65.9 \%$ (Additional file 3). Among CHW, $50.4 \%$ had AL for children $5-15 \mathrm{~kg}$ in stock (a package of six tablets) and availability of other weight/age formulations was less than $5 \%$. SP was available in $73.9 \%$ of public health facilities and was not found among CHWs. Oral quinine was available in $87.7 \%$ of public health facilities and among $2.3 \%$ of $\mathrm{CHWs}$.

Availability of malaria blood testing was $94.7 \%$ among public health facilities and $68.4 \%$ among CHWs. Malaria blood testing stocking rates were largely attributed to the availability of RDT.

The readiness of public-sector outlets for malaria case management, defined as stocking both quality-assured $\mathrm{ACT}$ and having malaria blood testing, was $89.0 \%$ among public health facilities and $49.7 \%$ among $\mathrm{CHWs}$.

\section{Private sector availability}

Among all screened private sector outlets, availability of anti-malarials was as follows: $85.8 \%$, private for-profit facilities; $94.6 \%$, pharmacies; $27.5 \%$, general retailers; and $67.7 \%$, itinerant drug vendors (Table 2 ).

Among the outlets stocking at least one anti-malarial in stock, 36.1\% had a quality-assured ACT. This was most commonly available among pharmacies (90.0\%) compared to private for-profit facilities, general retailers, and itinerant drug vendors $(36.4,35.4$ and $34.2 \%$, respectively). $31.3 \%$ of ACTs in the private sector were marked 
Table 1 Availability of anti-malarial and malaria blood testing among all public sector outlets screened

\begin{tabular}{|c|c|c|c|}
\hline & $\begin{array}{l}\text { Public health facility } \\
\%(95 \% \mathrm{Cl})\end{array}$ & $\begin{array}{l}\text { CHW } \\
\%(95 \% \mathrm{Cl})\end{array}$ & $\begin{array}{l}\text { Total public sector } \\
\%(95 \% \mathrm{Cl})\end{array}$ \\
\hline Availability of: & $N=298$ & $N=145$ & $\mathbf{N}=536$ \\
\hline Any anti-malarial & $95.0(90.3,97.4)$ & $59.4(40.2,76.1)$ & $72.6(58.1,83.5)$ \\
\hline Quality-assured ACT & $89.9(83.9,93.8)$ & $54.8(32.2,75.7)$ & $59.4(43.6,73.4)$ \\
\hline Quality ACT with the 'green leaf'logo & $3.0(0.9,9.8)$ & $0.6(0.1,4.3)$ & $4.7(2.0,10.8)$ \\
\hline Sulfadoxine-pyrimethamine & $73.9(63.9,81.9)$ & $0.0(-)$ & $20.6(14.9,27.7)$ \\
\hline Oral quinine & $87.7(82.7,91.3)$ & $2.3(0.4,11.7)$ & $33.2(25.0,42.6)$ \\
\hline Chloroquine & $0.4(0.1,1.6)$ & $0.0(-)$ & $1.3(0.5,3.5)$ \\
\hline Oral artemisinin monotherapy & $0.0(-)$ & $0.0(-)$ & $0.0(-)$ \\
\hline Artesunate injection & $5.3(1.6,16.6)$ & $0.0(-)$ & $1.3(0.4,4.1)$ \\
\hline Artemether injection & $6.2(2.1,16.7)$ & $0.0(-)$ & $5.5(2.5,11.8)$ \\
\hline Quinine injection & $79.3(69.5,86.5)$ & $4.5(0.8,22.1)$ & $32.2(23.9,41.9)$ \\
\hline Availability of: & $N=298$ & $N=145$ & $N=536$ \\
\hline Any diagnostic test & $94.7(90.1,97.2)$ & $68.4(47.3,84.0)$ & $69.4(56.9,79.6)$ \\
\hline Microscopy & $28.7(21.4,37.2)$ & $0.9(0.1,5.1)$ & $8.9(6.0,13.0)$ \\
\hline RDT & $94.4(89.8,96.9)$ & $68.4(47.3,84.0)$ & $68.355 .8,78.7)$ \\
\hline Readiness for malaria case management: & $N=298$ & $N=145$ & $N=536$ \\
\hline Quality-assured ACT and malaria testing available & $89.0(82.7,93.2)$ & $49.7(28.4,71.2)$ & $53.7(39.2,67.6)$ \\
\hline Quality-assured ACT no malaria testing available & $1.0(0.2,3.6)$ & $5.1(2.3,11.0)$ & $5.7(3.1,10.2)$ \\
\hline
\end{tabular}

${ }^{a}$ Includes public non-for profit sector $(\mathrm{N}=93)$

Table 2 Availability of anti-malarial and malaria blood testing among the private outlets

\begin{tabular}{|c|c|c|c|c|c|}
\hline & $\begin{array}{l}\text { Private for-profit facility } \\
\%(95 \% \mathrm{Cl})\end{array}$ & $\begin{array}{l}\text { Pharmacy } \\
\%(95 \% \mathrm{Cl})\end{array}$ & $\begin{array}{l}\text { General retailer } \\
\%(95 \% \mathrm{Cl})\end{array}$ & $\begin{array}{l}\text { Itinerant drug vendor } \\
\%(95 \% \mathrm{Cl})\end{array}$ & $\begin{array}{l}\text { Total private sector }^{\mathrm{a}} \\
\%(95 \% \mathrm{Cl})\end{array}$ \\
\hline Among all screened outlets: & $N=262$ & $N=176$ & $N=5622$ & $N=632$ & $N=6724$ \\
\hline Availability of any anti-malarial & $85.8(77.6,91.3)$ & $94.6(76.5,99.0)$ & $27.5(21.9,34.0)$ & $67.7(38.8,87.4)$ & $33.3(30.2,36.7)$ \\
\hline $\begin{array}{l}\text { Among anti-malarial stocking outlets, } \\
\text { availability of: }\end{array}$ & $N=222$ & $N=170$ & $N=1388$ & $N=468$ & $N=2278$ \\
\hline Quality-assured ACT & $36.4(23.0,52.2)$ & $90.0(75.0,96.5)$ & $35.4(27.9,43.8)$ & $34.2(22.3,48.4)$ & $36.1(27.7,45.5)$ \\
\hline Quality-assured AL & $35.9(22.7,51.6)$ & $89.5(74.9,96.1)$ & $35.1(27.5,43.6)$ & $34.2(22.3,48.4)$ & $35.9(27.5,45.3)$ \\
\hline $\begin{array}{l}\text { Quality ACT with the 'green leaf' } \\
\text { logo }\end{array}$ & $25.0(15.5,37.6)$ & $0.1(0.0,0.8)$ & $33.2(25.7,41.7)$ & $28.9(17.1,44.6)$ & $31.3(23.0,41.0)$ \\
\hline Non quality-assured ACT & $19.3(13.3,27.2)$ & $100.0(-)$ & $12.7(8.4,18.9)$ & $13.0(7.5,21.6)$ & $14.8(10.6,20.3)$ \\
\hline Sulfadoxine-pyrimethamine & $24.6(16.2,35.5)$ & $56.6(39.5,72.3)$ & $29.4(19.8,41.4)$ & $68.1(42.9,85.8)$ & $36.4(22.1,53.7)$ \\
\hline Oral quinine & $70.5(64.0,76.3)$ & $67.6(46.7,83.2)$ & $34.3(21.1,50.5)$ & $60.1(36.1,80.1)$ & $42.5(26.1,60.7)$ \\
\hline Chloroquine & 11.1 & $0.0(-)$ & $71.3(54.7,83.6)$ & $38.4(19.0,62.4)$ & $59.2(39.9,76.1)$ \\
\hline Other non-artemisinin & $3.4(1.3,8.4)$ & $15.6(8.6,26.6)$ & $2.1(1.3,3.4)$ & $8.6(5.7,12.8)$ & $3.6(2.1,6.0)$ \\
\hline Oral artemisinin monotherapy & $0.0(-)$ & $0.0(-)$ & $0.0(-)$ & $0.0(-)$ & $0.0(-)$ \\
\hline Artesunate injection & $1.5(0.5,4.3)$ & $23.9(14.5,36.8)$ & $0.0(-)$ & $0.0(-)$ & $0.5(0.2,0.9)$ \\
\hline Artemether injection & $28.8(19.9,39.7)$ & $70.3(55.5,81.8)$ & $0.8(0.3,2.2)$ & $0.0(-)$ & $4.1(2.9,5.8)$ \\
\hline Quinine injection & $82.7(75.7,88.0)$ & $30.4(19.0,44.9)$ & $1.7(0.8,3.7)$ & $0.0(-)$ & $8.7(6.4,11.8)$ \\
\hline $\begin{array}{l}\text { Among outlets stocking anti-malarials } \\
\text { today or within the past } 3 \text { months, } \\
\text { availability of: }\end{array}$ & $N=233$ & $\mathbf{N}=170$ & $N=1530$ & $N=496$ & $N=2459$ \\
\hline Any diagnostic test & $39.2(30.6,48.5)$ & $5.0(1.4,16.0)$ & $0.1(0.0,0.3)$ & $0.0(-)$ & $3.3(2.3,4.7)$ \\
\hline Malaria microscopy & $17.9(8.7,33.2)$ & $0.0(-)$ & $0.0(-)$ & $0.0(-)$ & $1.5(0.8,2.8)$ \\
\hline RDT & $26.1(16.8,38.3)$ & $5.0(1.4,16.0)$ & $0.1(0.0,0.3)$ & $0.0(-)$ & $2.2(1.3,3.8)$ \\
\hline
\end{tabular}

a Total private sector includes 32 drug stores 
with the 'green leaf' logo. Adult quality-assured ACT was available in $24.6 \%$ of private-sector outlets. The three child formulations were available in less than $15 \%$ of the private sector (Additional file 4).

Chloroquine was available in $59.2 \%$ of the private sector followed by oral quinine (42.5\%) and SP (36.4\%), though there were several differences across outlet types. For example, chloroquine was most commonly stocked by general retailers $(71.3 \%)$ while SP was most commonly available among itinerant drug vendors $(68.1 \%)$ and oral quinine was available in $70.5 \%$ private for-profit facilities.

\section{Anti-malarial market share}

Figure 1 shows the market share of different categories of anti-malarials sold or distributed in the 7 days prior to the survey. A total of 25,427 anti-malarial AETDs were reportedly distributed in seven days before the survey.

$21.5 \%$ of the anti-malarial market share was distributed by the public sector, which was comprised mostly of quality-assured ACT without the 'green leaf' logo (9.9\% of total market share) and of SP (6.5\% of the total market).

Almost $80 \%$ of the anti-malarials distributed were through the private sector (78.5\%). Quality-assured ACT with the 'green leaf' logo comprised $15.6 \%$ of the total anti-malarial market share, followed by non-quality assured ACT (without the logo), which comprised 14.3\%. SP made up the largest market share of non-artemisinin therapies $(24.7 \%)$, followed by chloroquine $(13.3 \%)$ and oral quinine (6.5\%).

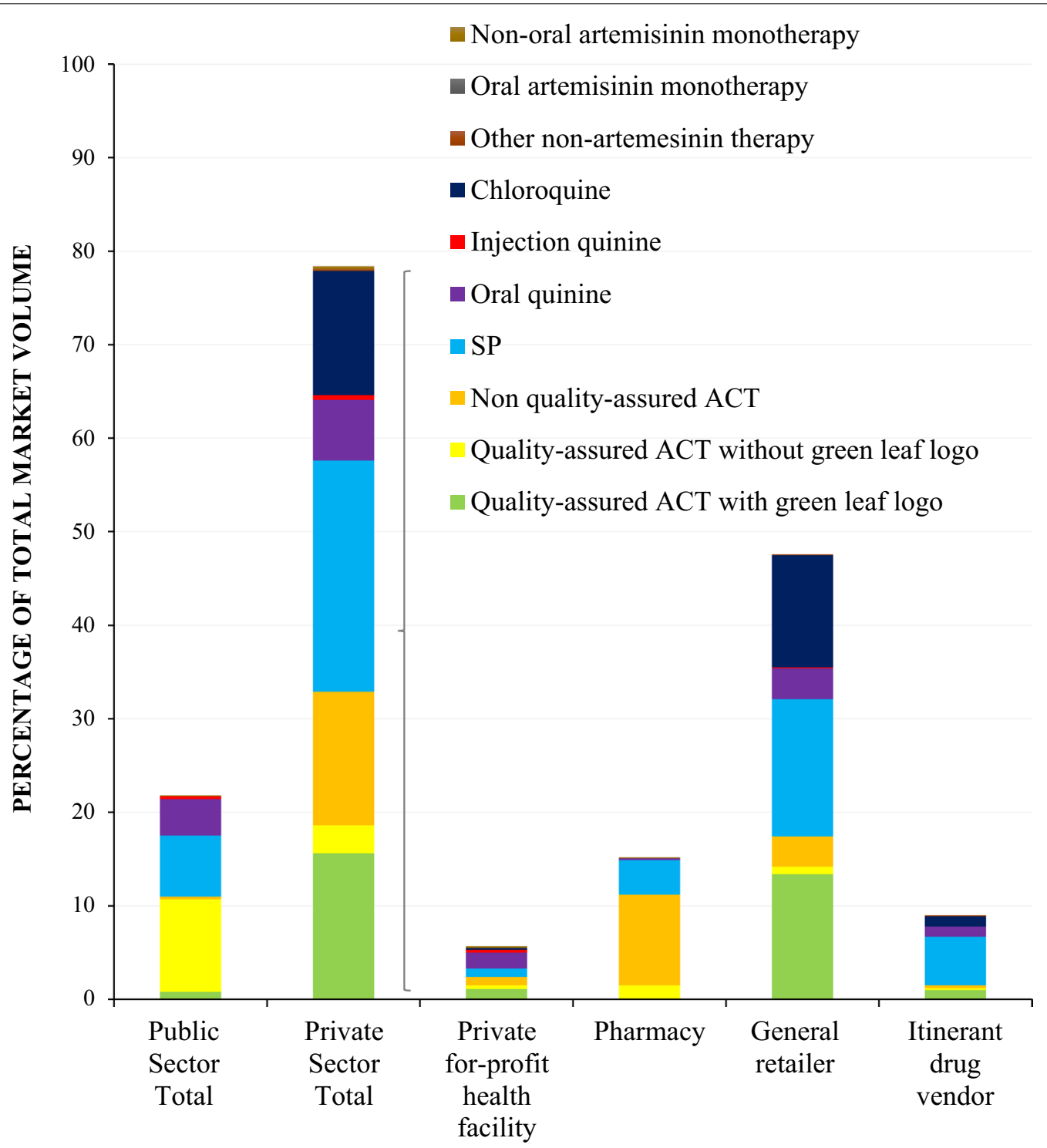

Fig. 1 Anti-malarial market share 
Overall, general retailers dominated the anti-malarial market, accounting for $47.6 \%$ of the total market share in Benin, and these providers distributed most of the quality-assured ACT with the 'green leaf' logo (13.4\% of total market share), SP (14.7\%), and chloroquine (12.0\%).

\section{Malaria diagnostic market share}

Figure 2 shows the diagnostic market share of different types of malaria tests administered in the seven days prior to the survey. A total of 6712 malaria test units, either microscopy or RDT, were reportedly distributed or used in the seven days prior the outlet survey.

Most of the malaria testing was performed through the public sector, which accounted for $82.2 \%$ of the total diagnostic testing market share. Microscopy testing was rare across both the public and the private sector, 14.8 and $6.8 \%$ respectively.

Within the private sector, malaria blood testing market share was dominated entirely by private for-profit health facilities since none of the other private sector outlets reportedly distributed or sold malaria testing in the seven days before the survey.

\section{Price}

Private sector price of AETD quality-assured ACT (\$1.35, inter quartile range [IQR] \$1.0, \$2.02) was three times more expensive than SP $(\$ 0.42$, IQR $\$ 0.34$, $\$ 0.51$ ) or chloroquine ( $\$ 0.41$, IQR $\$ 0.41-\$ 0.42)$. The price of AETD quinine was \$3.54 (IQR \$2.83-\$4.25) 2.6 times more expensive than one quality-assured ACT.

\section{Provider perceptions of most effective treatment}

When providers were asked what they perceived to be the most effective anti-malarial for the treatment of uncomplicated malaria in children or adults, results from the public sector illustrate that most providers cited an ACT. Among public health facility providers, 94.6 and $96.4 \%$ perceived ACTs was the most effective treatment in adults and in children respectively (Figs. 3, 4). Specific to the question regarding the most effective treatment for adults, $37.2 \%$ of CHWs responded that they did not know, while $59.8 \%$ perceived ACT as the most effective for an adult and $91.8 \%$ of them perceived an ACT as the most effective for children.

In the private sector, $62.7 \%$ of private for-profit and $93 \%$ of pharmacy providers cited an ACT as the most effective treatment for adults, and 73.4 and $94.9 \%$ respectively cited this as most effective for children. Non-artemisinin therapies, typically chloroquine and quinine, were cited as most effective treatment among general retailers (chloroquine, children: $24.8 \%$; adults: $34.4 \%$; quinine, children: 15.4\%; adults: $18.3 \%$ ) and itinerant drug vendors (chloroquine, children: $17.6 \%$; adults: $29.8 \%$; quinine, children: 43.1\%; adults: $30.5 \%)$. SP was commonly cited as the most effective treatment for adults by itinerant drug vendors $(29.8 \%)$.

\section{Discussion}

The 2016 outlet survey provided a complete picture of the malaria testing and treatment landscape across the public and private sectors, providing information on availability, market share, price, and provider perceptions. The

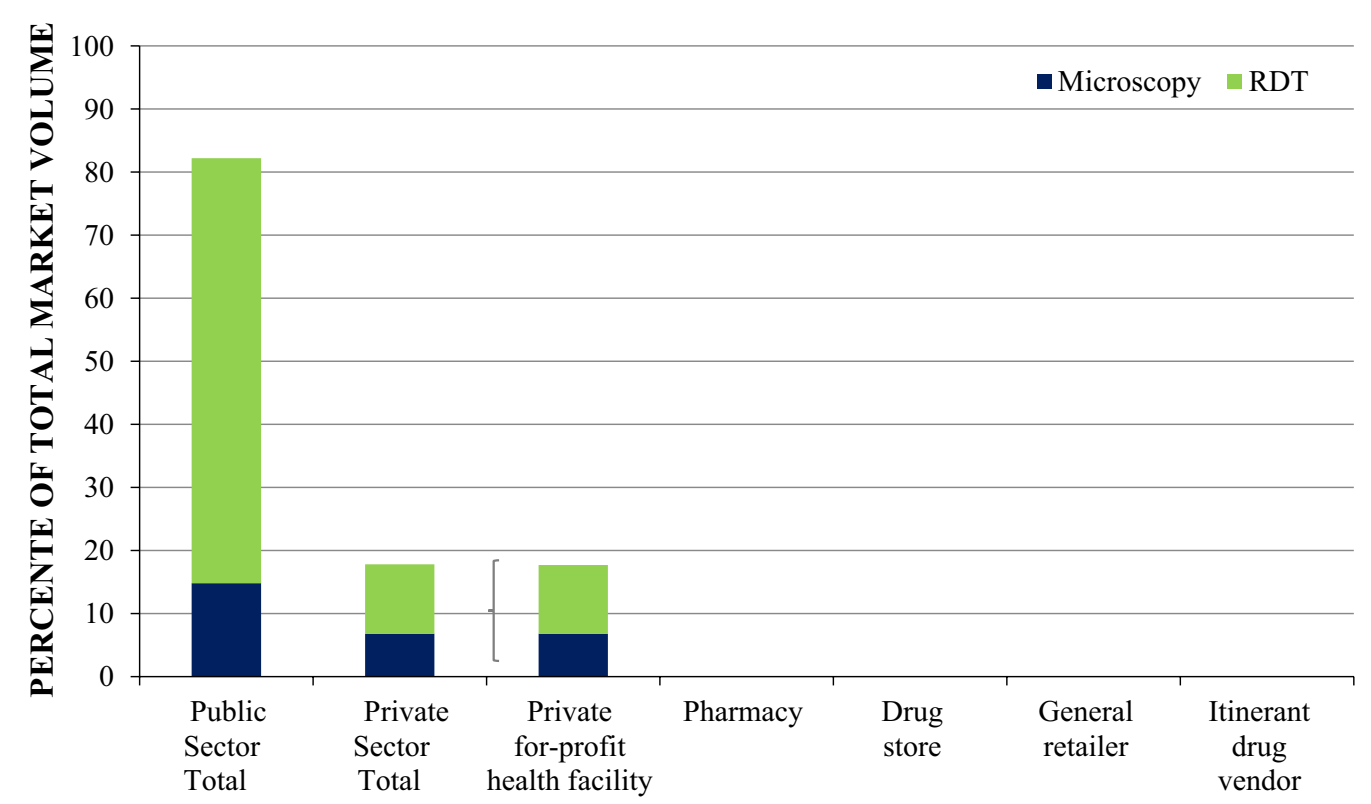

Fig. 2 Diagnostic market share 


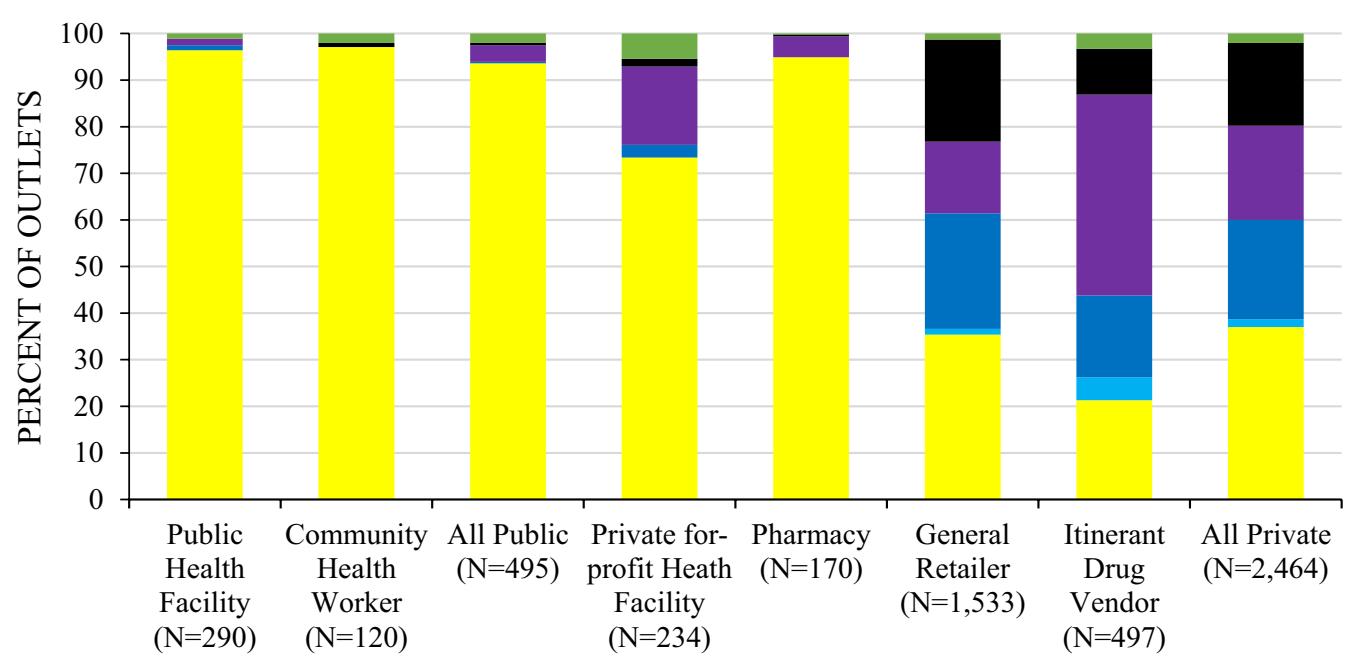

ACT $\square$ SP Chloroquine $\square$ Quinine $\square$ Don't know $\square$ Other

Fig. 3 Providers' perceptions of the most effective treatment for an uncomplicated malaria in a child

findings point to recommendations for improving private-sector malaria case management in Benin.

\section{Public sector readiness for appropriate malaria case management}

Public health facilities showed high readiness for appropriate case management in Benin. There was nearly universal coverage of quality-assured ACT treatment and malaria blood testing in these facilities. These findings reflect national strategies that have been in place since 2011, which stipulate confirmatory testing prior to treatment for all ages and at all levels of care [6]. The current levels of readiness reflect a substantial increase from diagnostic availability measured in 2011, where just over half of the public health facilities had malaria testing available (56.8\%) [17], illustrating that national policy has been successful in increasing access to confirmatory testing in this sector.

Three-quarters of public health facilities had SP available for IPTp treatment, reflecting an increase over time, from $17.2 \%$ in 2011 and $44.7 \%$ in 2014. This suggests substantial progress has been made with regards to the scale-up of SP for IPTp [17, 18]. This is in-line with recent national strategies to increase access to SP, including changes to the dosing regimen, and efforts to provide malaria services free of charge to pregnant women [6]. Availability of oral quinine, recommended for the treatment of uncomplicated malaria in pregnancy during the first trimester, was also high, with over $85 \%$ of public health facilities stocking this medicine. These findings illustrate overall readiness among public health facilities to manage malaria in pregnant women.
According to the 2015 national guidelines, injectable quinine followed by oral quinine are still the recommended treatment for severe malaria, which could explain the high levels of quinine availability in public health facilities. However, it is possible that quinine is being used for uncomplicated malaria given it is widely available throughout all types of public health facilities. Quinine should only be administered at hospitals, which would be equipped to manage patients with severe malaria. Furthermore, while a full course of quinine tablets are indicated for treatment of severe malaria, this should only be administered after a primary treatment with injectable quinine. However, market share data illustrate that oral quinine comprises one in every fifth antimalarial distributed in the public sector, while quinine injection is negligible, suggesting that oral quinine may be routinely administered for uncomplicated malaria. Indeed, a recent household study in southern Benin found quinine was the second most used anti-malarial for self-medication (after ACT) suggesting that efforts are needed to ensure the appropriate administration of this anti-malarial [21]. Despite the updated WHO standards, artesunate availability remains low (5.3\%). Efforts are currently underway to identify the barriers to increasing injectable artesunate use for severe malaria treatment in Benin [6].

Since 2014, the reach of the public sector has been extended to the community-level through the training and equipping of $\mathrm{CHWs}$ with malaria case management skills and supplies (AL and RDT). Since then, several investments have been made to increase the capacity 


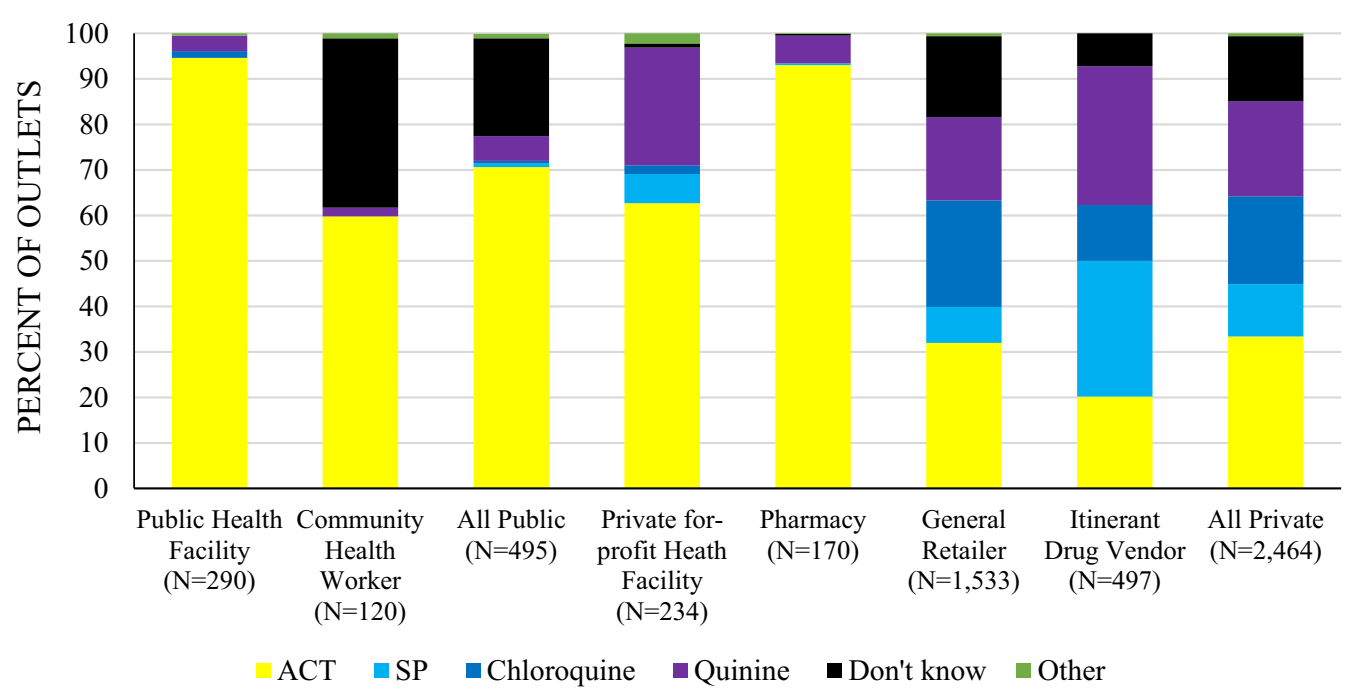

Fig. 4 Providers' perceptions of the most effective treatment for an uncomplicated malaria in an adult

and coordination of these providers [6]. The results from this survey illustrate how more than half of the CHWs had anti-malarials in stock, namely quality-assured ACT, and almost $70 \%$ had RDTs. The availability findings also reflect promising changes from earlier survey rounds where availability of ACT in 2011 was less than $50 \%$ and the availability of RDT was negligible $(<5 \%)$. Furthermore, most CHWs perceived ACT to be the most effective treatment for uncomplicated malaria in adults and children. These findings point to the success of a national level campaign to scale-up, train, and supply CHWs to provide ACT and blood testing services. Key areas to address may be improving CHW awareness of the most effective anti-malarial for adults given $40 \%$ did not know what this was, and to maintain supply of RDTs as a means to increase access to confirmatory testing.

\section{Role of the private sector in malaria case management}

Results from the study confirmed the dominant role of the private sector across Benin, where almost $80 \%$ of all anti-malarials passed through this sector, mainly through general retailers-which accounted for almost half of the anti-malarial market share in $2016(47.6 \%)$ [17, 18]. Of the 5600 general retail outlets that were screened for anti-malarials, over one in four had anti-malarials in stock, reflecting a three-fold increase from previous surveys. General retailers as a source of anti-malarial treatment have also been documented in other countries, including Madagascar, Myanmar, and Cambodia [22-24], and were also a common source of treatment in Benin as evidenced in a population based survey [25]. The results also point to the importance of itinerant drug vendors, of which over half of those surveyed had anti-malarials available, and comprised around one tenth of the antimalarial market share. Trend data also illustrate how the combined anti-malarial market share of general retailers and itinerant drug vendors, subsequently referred to as the 'informal' private sector, has increased over time from $30.9 \%$ in $2011,40.1 \%$ in 2014 , to $56.8 \%$ in 2016 [17, $18]$, illustrating the increasing relevancy of these outlets in the delivery of anti-malarial treatment. It is unclear why an increase in the informal market composition has been observed. Given there is little regulation of the private sector in Benin, this growth of the informal sector market composition may reflect a natural evolution of the market to meet consumer demand for anti-malarials, and perhaps these outlets are more accessible to patients. In absence of regulation, general retailers and itinerant drug vendors have perhaps responded to consumer demand by stocking anti-malarials in addition to other products.

Given a large portion of the private-sector case management is being channeled through these informal outlets, there may be several opportunities to strengthen the malaria case management services provided by these vendors. There are examples in the literature of innovative strategies that have focused on general retailers and itinerant drug vendors to improve access to qualityassured ACT [24]. There is also a growing body of support for itinerant drug vendors as a means to improve home-based management of malaria [26, 27], and these mobile providers have been cited as a useful means to improve the provision of care for malaria [28]. In Benin, there is also documentation of 'associations' of drug vendors, which operate within traditional markets and perform quasi-regulatory functions [11]. The quasi-formal nature of these vendors may make them suitable for 
accreditation programmes as a means to further regulate, supervise, and engage with the private sector in both ACT and RDT distribution. Such strategies, done in collaboration with the public sector, may help to complement rather than compete with the existing $\mathrm{CHW}$ programme. Considering the informal sector in the accreditation process may be an important strategy to accelerate coverage of appropriate case management in Benin.

\section{Readiness of the private sector in malaria case management}

The private sector was generally less well-equipped to test and appropriately treat malaria infections as compared with the public sector. Only one-third of private-sector outlets were stocking quality-assured ACT. Non-artemisinin therapies were more commonly available and distributed. Availability of malaria testing was also negligible and consistent with these findings, most malaria tests were administered by the public sector, which comprised over $80 \%$ of the diagnostic market share. Given most private-sector outlets were not stocking malaria tests suggests that presumptive treatment is widespread.

\section{Availability and market share of ACT}

While the AMFm or subsequent CPM programme was not implemented in Benin, most of the quality-assured ACT reportedly distributed in the private sector had the AMFm 'green leaf' logo. This indicates leakage of antimalarials' from other countries and suggests that antimalarials are being illegally traded into non-subsidized private markets.

The widespread availability and distribution of quality-assured ACT with the logo is perhaps not surprising considering Benin's supply chain [11]. The domestic antimalarial market in Benin is relatively small, with few local manufacturers, so the country's supply relies heavily on imports. Many of the anti-malarial supplies are obtained from more developed pharmaceutical markets in surrounding countries, most notably Nigeria, and imported largely though the informal sector. Thus, it is quite likely that products with the 'green leaf' logo-a marker of the subsidized CPM ACT-have leaked into Benin's privatesector outlets through neighbouring Nigeria. In fact, prior to the AMFm, the importation of medicines illegally from Nigeria was noted as commonplace, with vendors citing ease of accessing cheap suppliers in Lagos as a key reason for the illegal import [11]. The widespread uptake of this illegally imported ACT speaks to the need for a national level programme targeting the private sector with subsidized quality-assured ACT to align the privatesector outlets with national treatment guidelines, as well as a need to strengthen border control and regulation.
Availability and distribution of other non-quality assured ACT was also high, comprising $14.3 \%$ of the antimalarial market and reflecting a slight increase from earlier survey rounds $[16,17]$. This is of concern given that non-quality assured ACT medicines have not received pre-qualification, meaning that these medicines have not necessarily been manufactured according to quality standards yielding safe and efficacious medicines. Moreover, non quality-assured ACT have an increased likelihood of being poor quality as evidenced by studies that have tested the pharmacological properties of the medicines [29]. The widespread presence of non-quality assured ACT is of concern given its presence on the market and use poses a threat to appropriate and effective malaria case management.

\section{Availability of different AL formulations}

While the strength of all first-line AL tablets for treatment of uncomplicated malaria is indeed the same, the implementation of the AL policy includes delivery of four different AL pack sizes (6, 12, 18 and 24 tablets) suitable for management of four different weight categories of patients $(5-14 ; 15-24 ; 25-34$ and $\geq 35 \mathrm{~kg})$. In the private sector, as well as the public sector, availability of the different weight categories was relatively poor. For example, in the private sector, only $11.4 \%$ of the private for-profit facilities and $58.6 \%$ of pharmacies had AL treatments for children under 5 .

Maintaining a consistent supply of age/weight appropriate commodities will be key to ensure that ACT commodities are administered according to the recommended age and weight band of each patient and to prevent medicine packages from being cut or tampered with. This is particularly important given evidence that AL treatment is up to six times more likely to be prescribed if the weight specific pack is in stock [30]. While several strategies are underway to better manage the supply and procurement of malaria commodities to avoid stock-outs, this has not been fully implemented. Temporary options may be to instruct providers to administer AL even if adequate AL pack sizes are not in stock. However, evidence suggests that this practice may compromise high levels of patients' adherence to AL [31] and incorrect dosing $[32,33]$. If adequate availability of firstline ACT treatments cannot be ensured, alternative AL preparations that do not depend on separate packaging, could also be considered [30].

\section{Availability and use of non-artemisinin therapies}

Over a decade after the change in first-line treatment for uncomplicated malaria, non-artemisinin therapies, including SP, oral quinine, and chloroquine, accounted for the majority $(57.7 \%)$ of the market share in the private 
sector. SP made up over half of the non-artemisinin therapies reportedly distributed. While most of the SP distribution was through itinerant drug vendors and general retailers, SP was also commonly distributed by pharmacies. The widespread distribution of this medicine implies that it is being used for malaria case management rather than exclusively for IPTp as recommended. Widespread availability and distribution of oral quinine, particularly among general retailers and itinerant drug vendors, also indicates this is being used for the treatment of uncomplicated malaria.

Widespread distribution of non-artemisinin therapies in Benin might be explained by a number of factors. This may in part be attributed to price, given that SP and chloroquine were three times less expensive than qualityassured ACT. Alternatively, access may also be an important factor. Non artemisinin therapies were more widely available than quality-assured ACT-particularly among general retailers where most anti-malarials were distributed. Another reason may be around provider perceptions of the most effective treatment for uncomplicated malaria. In 2016, most of the itinerant drug vendors and general retailers perceived non-artemisinin therapies (SP, chloroquine, or quinine) as the most effective treatment for uncomplicated malaria.

To improve private-sector case management, removal of non-artemisinin therapies from the market is paramount and new strategies are necessary to curtail their consumption and promote the use of quality-assured $\mathrm{ACT}$ and RDT in the private sector. Several programmes have been implemented across sub-Saharan Africa to improve private sector readiness for appropriate malaria case management that could be relevant in the Benin context. A similar nation-wide subsidy to that of the AMFm may be an immediate means to overcome ACT access and affordability issues for this treatment, as evidence by the pilot initiative [34,35]. Once barriers related to access of quality-assured ACT have been addressed, mass-media behaviour change campaigns may be a particularly effective strategy in Benin to increase awareness of the first-line treatment and to promote demand for the quality ACT product. Several studies have demonstrated how consumer demand is associated with treatment and how patient preferences influence provider dispensing behaviour [36-39]. Specifically in Benin, qualitative research found that provider stocking decisions were overwhelmingly driven by patient demand, which led some outlets not to stock ACT [11]. Furthermore, provider training and supervision may also be merited to improve the quality of case management practices, including accreditation of outlets as previously discussed. Such multi-pronged strategies are likely to improve malaria case management and can improve private sector readiness and performance, as has been demonstrated in other contexts [12].

\section{Availability of oral artemisinin monotherapy}

Oral artemisinin monotherapy poses a serious threat to the continued efficacy of artemisinins, and as such this anti-malarial was banned in Benin in 2008. In 2016, no oral artemisinin monotherapy was detected in the market. This is of promise given ACTwatch outlet survey findings from neighboring Nigeria which show that availability of oral artemisinin monotherapy in the private sector has increased from $24.6 \%$ in 2013 to $37.3 \%$ in 2015 [40]. Given that Nigeria appears to be a source of supply of anti-malarials to Benin's private sector market, it is important that availability of oral artemisinin monotherapy in the market is routinely monitored. Mystery clients to detect unwanted or banned medicines may be a useful method to do this [41].

\section{Limitations}

The ACTwatch outlet survey design has limitations that have been documented and reported $[9,15,19]$. One point to mention is that while anti-malarial audits were carried out by researchers, sales volumes were reported by the provider and these responses were open to positive response bias. The pros and cons of using self-reported sales volumes, versus other methods to capture market share such as sale inventory audits or exit interviewers, suggests that there are advantages and disadvantages of different methods but no method is gold standard and each has its own limitations [42].

Other specific limitations to Benin's outlet survey include the use of two different forms of data collection (electronic and paper questionnaires). While electronic data collection has the advantage of recording the data instantly with all the relevant checks and skip patterns built into the programme, it may have had an impact on respondents' fear that they were being recorded or investigated. In addition, some itinerant vendors could have been missed during the survey given these vendors may work late at night and, for security reasons, interviewers only worked during the day and early evening.

\section{Conclusions}

The public sector in Benin is typically well equipped to test and appropriately treat malaria according to national treatment guidelines. However, the private sector is responsible for most of the anti-malarial distribution, typically through general retailers, and this channel most commonly distributes non-artemisinin therapies. There is also evidence of leakage of subsidized ACT from neighbouring countries. A national strategy to scale up access to first-line, quality-assured, subsidized treatment as a 
means to improve coverage and quality of malaria case management services is needed. Strategies to increase coverage of malaria commodities should be supported by interventions to address provider perceptions, as well as consumer behaviours, and innovative approaches to either engage or regulate Benin's informal private sector are needed.

\section{Additional files}

Additional file 1. Sampling weights.

Additional file 2. Detailed sample description.

Additional file 3. Availability of quality-assured AL among all screened public sector outlets.

Additional file 4. Availability of quality-assured AL among anti-malarial stocking private outlets.

\section{Abbreviations}

ABSM : Association Beninoise pour le Marketing Social; ACT: artemisininbased combination therapy; AL: artemether-lumefantrine; AETD: adult equivalent treatment dose; AMFm: affordable medicines facility for malaria; CHW: community health worker; CFA: Communauté Financière Africaine; CPM: co-payment mechanism; IPTp: intermittent treatment as prevention during pregnancy; IQR: inter quartile range; NMCP: National Malaria Control Programme; RDT: rapid diagnostic test; WHO: World Health Organization; SP: sulfadoxine-pyrimethamine; USA: United States of America.

\section{Authors' contributions}

The manuscript was conceived and drafted by members of the ACTwatch Group: Justin Rahariniaina, Catherine A. Hurley, Megan Littrell, Kathryn A. O'Connell. Data cleaning and analysis were completed by members of the ACTwatch Group: Kevin Duff, Justin Rahariniaina, Anna Fulton. CZ, ABZ provided assisted with interpretation of the study findings. CZ, ABZ provided assisted with interpretation of the study findings. All authors read and approved the final manuscript." Please confirm us to proceed further.

\section{Author details}

1 Population Services International, 1120 19th St NW Suite 600, Washington, DC 20036, USA. ${ }^{2}$ Association Beninoise pour le Marketing Social, Lot 919 Immeuble Montcho, Sikecodji, Cotonou, Republic of Benin. ${ }^{3}$ Programme National de Lutte contre le Paludisme, Ministère de la Santé, Cotonou, Benin.

\section{Acknowledgements}

We would like to thank Sitraka Ramamonjisoa for his assistance during the data collection and the team at ABMS for their support during the outlet survey. The authors are grateful to country teams in Benin who undertook the surveys and to the study participants for their time and participation.

\section{ACTwatch Group (2008-2017)}

Dr. Louis Akulayi; Angela Alum; Andrew Andrada; Julie Archer; Ekundayo D. Arogundade; Erick Auko; Abdul R. Badru; Dr. Katie Bates; Dr. Paul Bouanchaud; Meghan Bruce; Katia Bruxvoort; Peter Buyungo; Angela Camilleri; Dr. Emily D. Carter; Dr. Steven Chapman; Nikki Charman; Dr. Desmond Chavasse; Robyn Cyr; Kevin Duff; Gylsain Guedegbe; Keith Esch; Illah Evance; Anna Fulton; Hellen Gataaka; Tarryn Haslam; Emily Harris; Christine Hong; Catharine Hurley; Whitney Isenhower; Enid Kaabunga; Baraka D Kaaya; Esther Kabui; Dr. Beth Kangwana; Lason Kapata; Henry Kaula; Gloria Kigo; Irene Kyomuhangi; Aliza Lailari; Sandra LeFevre; Dr. Megan Littrell (Principal Investigator, 2014-2017); Greta Martin; Daniel Michael; Erik Monroe; Godefroid Mpanya; Felton Mpasela; Felix Mulama; Dr. Anne Musuva; Julius Ngigi; Edward Ngoma; Marjorie Norman; Bernard Nyauchi; Dr. Kathryn A. O'Connell (Principal Investigator, 20082012); Carolyne Ochieng; Edna Ogada; Linda Ongwenyi; Ricki Orford; Saysana Phanalasy; Stephen Poyer; Dr. Justin Rahariniaina; Jacky Raharinjatovo; Lanto Razafindralambo; Solofo Razakamiadana; Christina Riley; Dr. John Rodgers; Dr.
Andria Rusk; Tanya Shewchuk; Simon Sensalire; Julianna Smith; Phok Sochea; Tsione Solomon; Raymond Sudoi; Martine Esther Tassiba; Katherine Thanel; Rachel Thompson; Mitsuru Toda; Chinazo Ujuju; Marie-Alix Valensi; Dr. Vamsi Vasireddy (Principal Investigator, 2013); Cynthia B. Whitman; Cyprien Zinsou.

\section{Competing interests}

The authors declare that they have no competing interests.

\section{Availability of data and materials}

The datasets generated during and/or analysed during the current study are available in the figshare repository https://doi.org/10.6084/ m9.figshare.c.3749747_D10.

\section{Ethics approval and consent to participate}

The 2016 outlet survey protocol received ethical approval from the Benin National Research Ethics Committee (Comité National d'Ethique pour la Recherche en Santé-No_54/MS/DC/SGM/DFR/CNPERS/SA) and from the PSI Research Ethics Board. Provider interviews and product audits were completed only after administration of a standard consent form. Providers had the option to end the interview at any point during the study. Standard measures were employed to maintain provider confidentiality and anonymity.

\section{Funding}

The Benin 2016 ACTwatch outlet survey and the production of this manuscripts received financial support from the Bill and Melinda Gates Foundation.

\section{Publisher's Note}

Springer Nature remains neutral with regard to jurisdictional claims in published maps and institutional affiliations.

Received: 20 February 2017 Accepted: 6 April 2017

Published online: 26 April 2017

\section{References}

1. WHO. World malaria report. Geneva: World Health Organization; 2016 World Health Organization website http://www.who.int/malaria/publications/world-malaria-report-2016/report/en/. Accessed 3 Apr 2017.

2. Yaya S, Ze A. Le fardeau socio-économique du paludisme: Une analyse économétrique. Quebec City: Presses de I'Université Laval; 2013.

3. ACTwatch Group. ACTwatch baseline and endline household survey results 2009-2012: Benin, Democratic Republic of Congo, Madagascar, Nigeria, Uganda, Zambia. Washington, DC. 2013. ACTwatch website. http://www.actwatch.info/sites/default/files/content/publications/ attachments/ACTwatch\%2520HH\%2520Report\%2520Multicountry\%252 OBaseline\%2520and\%2520Endline.pdf. Accessed 3 Apr 2017.

4. ICF Macro. Enquête Démographique et de Santé du Bénin 2011-2012. Calverton, Maryland, USA. 2013. Demographic and Health Survey website. http://dhsprogram.com/publications/publication-FR270-DHS-FinalReports.cfm. Accessed Apr 42017.

5. World Bank. Les efforts du Bénin pour la réduction de la pauvreté (The efforts of Benin to reduce poverty). Cotonou, Benin. 2014. International Monetary Fund website. https://www.imf.org/external/french/pubs/ft/ scr/2011/cr11307f.pdf.

6. PMI. President's malaria initiative Benin malaria operational plan. 2016. PMI website. https://www.pmi.gov/where-we-work/benin. Accessed 4 Apr 2017

7. PMI. President's malaria initiative Benin malaria operational plan. 2010. PMI website. https://www.pmi.gov/where-we-work/benin. Accessed 4 Apr 2017.

8. USAID. Global health initiative: Benin country strategy. 2011. US Global Health Programmes Website. https://www.ghi.gov/wherewework/profiles/benin.html. Accessed 4 Apr 2017.

9. O'Connell KA, Gatakaa H, Poyer S, Njogu J, Evance I, Munroe E, et al. Got ACTs? Availability, price, market share and provider knowledge of anti-malarial medicines in public and private sector outlets in six malariaendemic countries. Malar J. 2011:10:326. 
10. République du Bénin. Directives Nationales de Prise en Charge des cas de Paludisme. 2015.

11. Torres Rueda S, Tougher S, Palafox B, Patouillard E, Goodman C, Hanson K, et al. A qualitative assessment of the private sector antimalarial distribution chain in Benin, 2009. Washington, DC. 2012. ACTwatch Website http://www.actwatch.info/sites/default/files/content/publications/ attachments/SCS\%20qualitative\%20report\%20Benin\%20FINAL\%20 20130117.pdf. Accessed 4 Apr 2017.

12. Tougher S, ACTwatch Group, Ye Y, Amuasi JH, Kourgueni IA, Thomson R, Goodman C, et al. Effect of the affordable medicines facility-malaria (AMFm) on the availability, price, and market share of quality-assured artemisinin-based combination therapies in seven countries: a beforeand-after analysis of outlet survey data. Lancet. 2012;380:1916-26.

13. Independent Evaluation Team. Independent Evaluation of Phase 1 of the affordable medicines facility-malaria (AMFm), Multi-Country Independent Evaluation Report: Final Report. Calverton, Maryland and London: ICF International and London School of Hygiene and Tropical Medicine. 2012. Global Fund Website. https://www.theglobalfund.org/media/3011/terg_ evaluation2013-2014thematicreviewamfm2012iephase1_report_en.pdf. Accessed 4 April 2017.

14. Global Fund. Use of a private sector co-payment mechanism to improve access to ACTs in the new funding model. 2013.

15. Shewchuk T, O'Connell KA, Goodman C, Hanson K, Chapman S, Chavasse $D$. The ACTwatch project: methods to describe anti-malarial markets in seven countries. Malar J. 2011;10:325.

16. ACTwatch Group. Benin Outlet Survey Report 2014 Washington, DC. 2016. ACTwatch website. http://www.actwatch.info/sites/default/ files/content/publications/attachments/ACTwatch\%20Study\%20 Reference\%20Document\%20Benin\%200utlet\%20Survey\%202014.pdf. Accessed Apr 42017.

17. ACTwatch Group. Benin outlet survey report 2011. Washington, DC. 2013. ACTwatch Website. http://www.actwatch.info/countries/benin/outletreports/2011. Accessed Apr 42017.

18. ACTwatch Group. Benin outlet survey report 2009. Washington, DC. 2011. ACTwatch website. http://www.actwatch.info/sites/default/files/content/ publications/attachments/Benin\%200utlet\%20Report\%202014\%20 \%28French\%29.pdf. Accessed 4 Apr 2017.

19. O'Connell KA, Poyer S, Solomon T, Munroe E, Patouillard E, Njogu J, et al. Methods for implementing a medicine outlet survey: lessons from the anti-malarial market. Malar J. 2013;12:52.

20. WHO. Guidelines for the treatment of malaria. 3rd ed. Geneva: World Health Organization; 2015. http://www.who.int/malaria/publications/ atoz/9789241549127/en/. Accessed 4 Apr 2017.

21. Agueh V, Badet M, Jérôme CS, Paraiso M, Azandjemè C, Metonnou C, et al. Prevalence and determinants of antimalarial self-medication in Southern Benin. Int J Trop Dis Health. 2016;18:1-11.

22. ACTwatch Group. Malaria market trends in Sub-Saharan Africa: 2009-2014. Washington, D.C. 2016. http://www.actwatch.info/sites/ default/files/content/publications/attachments/SSA\%20Brief_FINAL_ NO_BLEEDS.pdf. Accessed 4 Apr 2017.

23. ACTwatch Group, Novotny J, Singh A, Dysoley L, Sovannaroth S, Rekol H. Evidence of successful malaria case management policy implementation in Cambodia: results from national ACTwatch outlet surveys. Malar J. 2016;15:194.

24. Khin HS, Aung T, Aung M, Thi A, Boxshall M, White C, ACTwatch Group. Using supply side evidence to inform oral artemisinin monotherapy replacement in Myanmar: a case study. Malar J. 2016:15:418.

25. ACTwatch Group. Household survey Republic of Benin 2011 Survey Report. Washington, DC. 2013. http://www.actwatch.info/sites/ default/files/content/publications/attachments/ACTwatch\%2OHH\%20 Report\%20Benin\%202011.pdf. Accessed 4 Apr 2017.

26. WHO. Scaling up home-based management of malaria: from research to implementation. Geneva: World Health Organization; 2004. http://www. who.int/tdr/publications/documents/scaling-malaria.pdf. Accessed 4 Apr 2017
27. WHO. The roll back malaria strategy for improving access to treatment through home management. Geneva: World Health Organization; 2005. http://www.who.int/malaria/publications/atoz/who_htm_ mal 2005_1101/en/. Accessed 4 Apr 2017.

28. USAID. National strategy for utilizing the potential of private practitioners in child survival. Washington, DC. 2002. United States Agency for International Development. http://pdf.usaid.gov/pdf_docs/Pnacp202.pdf. Accessed 11 Apr 2017.

29. ACT Consortium Drug Quality Project Team. Quality of artemisinin-containing antimalarials in Tanzania's Private Sector-results from a nationally representative outlet survey. Am J Trop Med Hyg. 2015;92:75-86.

30. Zurovac D, Tibenderana JK, Nankabirwa J, Ssekitooleko J, Njogu JN, Rwakimari JB, et al. Malaria case-management under artemether-lumefantrine treatment policy in Uganda. Malar J. 2008;7:181.

31. Piola P, Fogg C, Bajunirwe F, Biraro S, Grandesso F, Ruzagira E, et al. Supervised versus unsupervised intake of six-dose artemether-lumefantrine for treatment of acute, uncomplicated Plasmodium falciparum malaria in Mbarara, Uganda: a randomised trial. Lancet. 2005:365:1467-73.

32. Zurovac D, Njogu J, Akhwale W, Hamer DH, Snow RW. Translation of artemether-lumefantrine treatment policy into paediatric clinical practice: an early experience from Kenya. Trop Med Int Health. 2008;13:99-107.

33. Zurovac D, Ndhlovu M, Sipilanyambe N, Chanda P, Hamer DH, Simon JL, et al. Paediatric malaria case-management with artemether-lumefantrine in Zambia: a repeat cross-sectional study. Malar J. 2007;6:31.

34. Willey BA, Tougher S, Ye Y, Mann AG, Thomson R, Kourgueni IA. Communicating the AMFm message: exploring the effect of communication and training interventions on private for-profit provider awareness and knowledge related to a multi-country anti-malarial subsidy intervention. Malar J. 2014;13:46.

35. Tougher S, Mann AG, Ye Y, Kourgueni IA, Thomson R, Amuasi JH, et al. Improving access to malaria medicine through private-sector subsidies in seven African countries. Health Aff. 2014:33:1576-85.

36. Thein ST, Sudhinaraset M, Khin HS, McFarland W, Aung T. Who continues to stock oral artemisinin monotherapy? Results of a provider survey in Myanmar. Malar J. 2016;15:334.

37. Palafox B, Patouillard E, Tougher S, Goodman C, Hanson K, Kleinschmidt I, et al. Understanding private sector antimalarial distribution chains: a cross-sectional mixed methods study in six malaria-endemic countries. PLOS ONE. 2014;9:e93763.

38. Manoff RK. Getting your message out with social marketing. Am J Trop Med Hyg. 1997;57(3):260-5.

39. Mangham LJ, Cundill B, Ezeoke O, Nwala E, Uzochukwu BS, Wiseman V, et al. Treatment of uncomplicated malaria at public health facilities and medicine retailers in south-eastern Nigeria. Malar J. 2011;10:155.

40. ACTwatch Group. ACTwatch Study reference document: Nigeria outlet survey 2015, Washington, DC. 2017. http://www.actwatch.info/sites/ default/files/content/publications/attachments/Nigeria_2015\%200S_ Reference\%20Document.pdf. Accessed 4 Apr 2017.

41. Tabernero P, Mayxay M, Culzoni MJ, Dwivedi P, Swamidoss I, Allan EL, et al. A repeat random survey of the prevalence of falsified and substandard antimalarials in the Lao PDR: a change for the better. Am J Trop Med Hyg. 2015:92:95-104.

42. Patouillard E, Kleinschmidt I, Hanson K, Pok S, Palafox B, Tougher S, et al. Comparative analysis of two methods for measuring sales volumes during malaria medicine outlet surveys. Malar J. 2013;12:311. 